\title{
IMPLEMENTASI WIRELESS DISTRIBUTION SYSTEM DAN AUTENTIKASI HOTSPOT MENGGUNAKAN RADIUS SERVER DI PT RIMBA MAKMUR UTAMA
}

\author{
(Implementation Of Hotspot Wireless Distribution System And Authentication Using \\ Radius Server in PT Rimba Makmur Utama)
}

\author{
Armand Fadilla ${ }^{1}$, Walidatush Sholihah ${ }^{1}$ \\ ${ }^{1}$ Program Studi Teknik Komputer, Sekolah Vokasi IPB \\ E-mail : walidah@apps.ipb.ac.id
}

Diterima 3 Juli 2021/Disetujui 8 Agustus 2021

\begin{abstract}
PT Rimba Makmur Utama is located on Jalan Kantin No.8 Kota Bogor. This private business company is engaged in the field of forest restoration on the island of Kalimantan, precisely in the Sampit region. This company's restoration is to save the forest from illegal logging and protect animals from extinction in the forests around the Sampit area. PT Rimba Makmur Utama is already using a hotspot so users can connect to the internet. However, problems arise when users move between rooms or places in the office but the wireless signal coverage cannot be reached. To overcome this, the solution is to build a Wireless Distribution System (WDS) network. WDS is a method that can be used to expand wireless networks by connecting multiple access points without using cables. Hotspot networks do not always provide fast and stable internet access. To overcome this, a user management system and bandwidth are needed using the Remote Authentication Dial In User Service protocol or RADIUS Server. User Manager is a RADIUS Server developed by MikroTik. All the area in the building have been covered with the internet. Users need username and password to connected to the network in the building.
\end{abstract}

Key Words: Bandwidth, Hotspot, RADIUS Server, User Manager, WDS

\section{PENDAHULUAN}

PT Rimba Makmur Utama Kota Bogor terletak di jalan Kantin No.8 Kota Bogor. Perusahaan bisnis swasta ini bergerak pada bidang restorasi hutan di pulau Kalimantan tepatnya di wilayah Sampit. Restorasi yang dilakukan perusahaan ini adalah untuk menyelamatkan hutan dari penebangan hutan secara liar dan melindungi hewan dari kepunahan di hutan sekitar wilayah Sampit. PT Rimba Makmur Utama dalah perusahaan swasta sehingga tidak terikat dengan pemerintah. PT Rimba Makmur Utama memiliki tiga kantor di tiga wilayah yang berbeda yaitu Bogor, Jakarta, dan Sampit. Ketiga perusahaan ini menyimpan informasi di dalam database server dan saling mengirimkan informasi dan berkomunikasi menggunakan jaringan internet. 
Jaringan tanpa kabel atau yang biasa disebut wireless belum sepenuhnya digunakan di PT Rimba Makmur Utama. Perangkat seperti komputer, laptop dan smartphone terhubung ke access point dengan menggunakan wireless untuk dapat mengakses internet. Namun antara access point satu dengan yang lainnya masih terhubung menggunakan kabel yang terhubung ke switch dan Access point yang terhubung pun masih menggunakan SSID yang berbeda - beda. Permasalahan timbul ketika pengguna berpindah ruangan atau tempat di dalam kantor namun jangkauan sinyal wireless tidak dapat dijangkau, sehingga pengguna harus kembali memasukan password untuk dapat terhubung ke access point dan mengakses internet. Solusi untuk mengatasi hal tersebut yaitu dengan membangun jaringan Wireless Distribution System (WDS). WDS adalah metode yang dapat digunakan untuk memperluas jaringan wireless ke seluruh gedung PT Rimba Makmur Utama dengan menghubungkan beberapa access point tanpa menggunakan kabel. Jaringan wireless yang menjangkau seluruh gedung ini membuat pengguna tidak perlu memasukkan password berulang-ulang untuk terkoneksi dengan internet.

Sistem Wireless Distribution System (WDS) tentunya memiliki kelebihan, dengan menerapkan sistem ini jangkauan sinyal wireless akan menjadi lebih luas sehingga ketika pengguna berpindah ruangan atau tempat yang masih dalam jangkauan internet, pengguna dapat dengan mudah menghubungkan perangkat laptop, komputer dan smartphone ke jaringan wireless. Kemudahan pengguna dalam mengakses wireless ini dapat menyebabkan koneksi internet menjadi tidak stabil karena tidak adanya pembatasan terhadap pengguna yang menggunakan jaringan internet. Untuk mengatasi permasalahan tersebut, perlu adanya pengembangan dalam wireless distribution system (WDS) berupa konfigurasi Remote Authentication Dial In User Service (RADIUS) Server berupa User Manager. User Manager adalah suatu fitur yang dimiliki oleh mikrotik untuk memberikan autentikasi pada wireless. Dengan menggunakan User Manager informasi pengguna akan disimpan dalam database. User Manager dapat digunakan juga untuk membatasi penggunaan bandwidth pengguna dengan memanajemen bandwidth dan pengguna menggunakan router MikroTik.

\section{METODE PENELITIAN}

Metode yang digunakan dalam proses penelitian ini terdiri atas empat tahap, yaitu analisis, perancangan, implementasi, dan pengujian, seperti ditunjukan pada Gambar 1.

\subsubsection{Analisis}

Tahap analisis merupakan tahap menganalisis permasalahan jaringan di PT Rimba Makmur Utama dicari dengan cara berdiskusi dengan pembimbing lapangan. Selain itu, dilakukan pula observasi di lingkungan kantor. 


\subsubsection{Perancangan}

Tahap perancangan merupakan tahap pembuatan rancangan untuk solusi dari permasalahan yang terjadi setelah melakukan analisis. Tahap perancangan akan memberikan gambaran mengenai alat dan bahan yang dibutuhkan serta topologi yang akan dibuat.

\subsubsection{Impelementasi}

Tahap implementasi adalah tahap menerapkan perancangan yang sudah dibuat dapat dioperasikan sesuai kebutuhan. Tahap ini merupakan tahap menerapkan konfigurasi Wireless Distribution System (WDS) dan RADIUS server.

\subsubsection{Pengujian}

Tahap pengujian adalah tahapan akhir untuk mengetahui hasil akhir dan menguji implementasi yang sudah diterapkan. Setelah tahap implementasi dibutuhkan pengujian bahwa sistem Wireless Distribution System (WDS) antar Access Point sudah saling terhubung. Pengujian juga dilakukan pada autentikasi hotspot yang dilakukan oleh pengguna untuk memastikan satu username bisa hanya bisa digunakan untuk satu user.

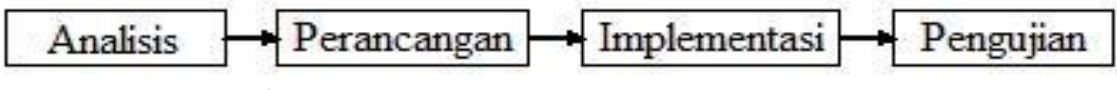

Gambar 1 Alur metode penelitian

\section{HASIL DAN PEMBAHASAN}

WDS menggunakan dua buah router mikrotik yaitu mikrotik RB951Ui - 2nD sebagai mikrotik utama dan mikrotik RB941-2nD sebagai mikrotik repeater. Kedua mikrotik ini mendukung fitur WDS namun mikrotik RB951Ui-2nD saja yang mendukung fitur user manager. Port ethernet 1 dihubungkan ke switch yang terhubung dengan router ISP agar mendapatkan IP secara DHCP dan terhubung ke internet. Port ethernet 3 pada mikrotik utama dihubungkan ke PC/laptop agar mikrotik dapat di konfigurasi. Sedangkan pada mikrotik repeater Port ethernet 2 dihubungkan ke PC/laptop agar mikrotik dapat di konfigurasi. Ketika sudah di konfigurasi, kedua router tersebut akan saling terhubung ke internet menggunakan WinBox. Pada User Manager akan dibuat tiga profile yaitu Admin, Manager, dan Staf. Admin akan dibuat lima account dengan bandwidth $1 \mathrm{Mbps}$. Manager akan dibuat 10 account dengan bandwidth 1 Mbps. Staf akan dibuat 15 account dengan bandwidth 512 Kbps. DHCP Server adalah perangkat jaringan yang memiliki kemampuan dalam memberikan atau meminjamkan alamat IP pada Komputer client yang terhubung dalam sebuah jaringan sehingga Komputer dapat berkomunikasi. DHCP dapat membantu menghemat penggunaan alamat IP karena alamat IP tidak 
perlu lagi diberikan secara permanen pada masing-masing komputer client (Miftah 2018). Konfigurasi dilakukan dengan berbeda network yang sudah terpasang pada instansi. Topologi dapat dilihat pada Gambar 2.

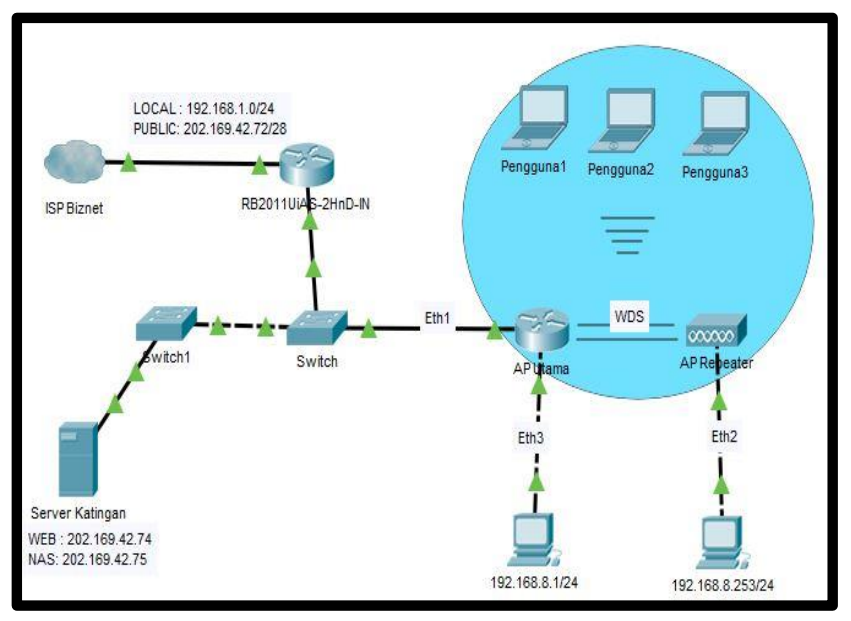

Gambar 1 Topologi WDS

\section{a. Konfigurasi Router Sebagai Access Point Utama}

Konfigurasi dilakukan di terminal mikrotik utama untuk mengkonfigurasi nama mikrotik dan DHCP. Mikrotik utama adalah mikrotik yang terhubung ke internet dan memancarkan sinyal wifi. Sinyal wifi akan diterima oleh pengguna dan mikrotik repeater. Pemberian nama dan DHCP router utama dapat dilihat pada Gambar 3. Baris pertama merupakan perintah system identity set name $=R \_$utama adalah untuk memberikan keterangan nama pada mikrotik utama. Baris kedua adalah perintah Ip dhcp-client add interface=ether 1 adalah agar port ethernet 1 pada mikrotik utama yang terhubung pada mikrotik yang terhubung ke ISP mendapatkan IP dhcp dari Internet Service Provider (ISP).

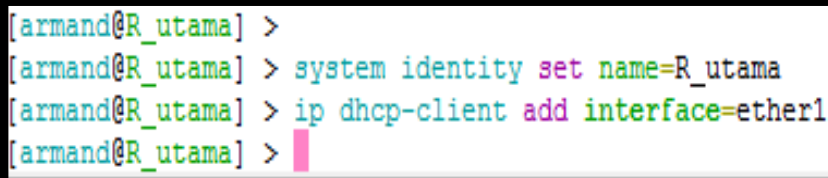

Gambar 2 Pemberian Nama dan DHCP Router utama

Selanjutnya konfigurasi membuat interface bridge untuk menghubungkan WDS. Interface bridge dibuat dengan memilih menu interface di mikrotik. Bridge berfungsi untuk melakukan penggabungan interface yang berbeda standard dan tipe (Chris 2012). Interface yang tergabung dalam satu bridge adalah interface wlan1 pada mikrotik utama dan interface wlan1 pada repeater. Pemberian nama interface dapat dilihat pada Gambar 4. 


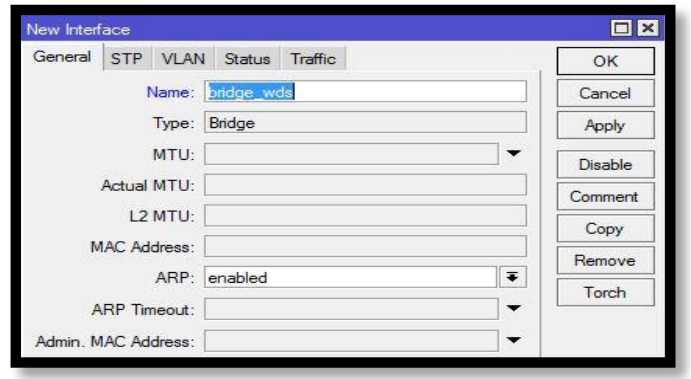

Gambar 3 Interface bridge_wds

Konfigurasi selanjutnya adalah pemberian IP address pada interface bridgewds. Pengaturan IP address dilakukan dengan memilih menu IP $\rightarrow$ address. IP address merupakan 32 bit bilangan biner dimana bisa dituliskan dengan bilangan desimal dengan dibagi menjadi 4 kolom dan dipisahkan dengan titik, penggunaan IP address adalah unik, artinya tidak diperbolehkan menggunakan IP address yang sama dalam satu jaringan (Sukaridhoto 2014). Pengisian IP address dapat dilihat pada Gambar 5.

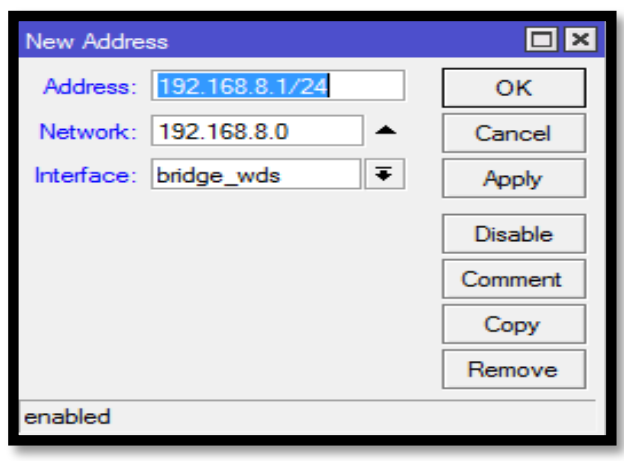

Gambar 4 IP address Bridge_wds

Tahap selanjutnya adalah pemberian DHCP Server. Konfigurasi IP DHCP server dapat dilihat pada Gambar 6. Perintah konfigurasi ip dhcp-server setup agar pengguna mendapatkan alamat IP secara otomatis dan terkoneksi ke internet. Interface yang digunakan adalah interface bridge_wds. Konfigurasi DHCP address space 192.168.8.0/24 adalah network yang digunakan pada interface bridge_wds. Konfigurasi DHCP address space 192.168.8.1/24 adalah gateway yang digunakan pada DHCP network yang berfungsi menghubungkan satu jaringan komputer dengan jaringan komputer lainnya. 


\section{Gambar 5 IP DHCP}

Pada menu interface wlan1 pengaturan mode wireless yang digunakan adalah ap bridge agar mikrotik berfungsi sebagai access point. Lebar frekuensi yang dipilih $2 \mathrm{GHz}-\mathrm{B} / \mathrm{G} / \mathrm{N}$ agar semua perangkat yang mendukung standart $802.11 \mathrm{~b}, 802.11 \mathrm{~g}$, dan $802.11 \mathrm{n}$ dapat terhubung ke perangkat router access point utama. Pada menu frequency yang dipilih 2432MHz dan SSID diberi nama "Katingan Mentaya" atau disesuaikan dengan keinginan.

Pada tab WDS mode yang dipilih adalah dynamic. Dengan menggunakan mode dynamic, interface WDS akan secara otomatis dibuat ketika sudah menemukan perangkat access point lain. WDS Default Bridge yang dipilih adalah interface bridge-wds yang telah dibuat sebelumnya. Interface WDS yang sudah dibuat akan muncul pada tab wireless dibawah interface wlan 1 karena interface master dari WDS adalah interface wlan1. Konfigurasi WDS dapat dilihat pada Gambar 7 dan Gambar 8.

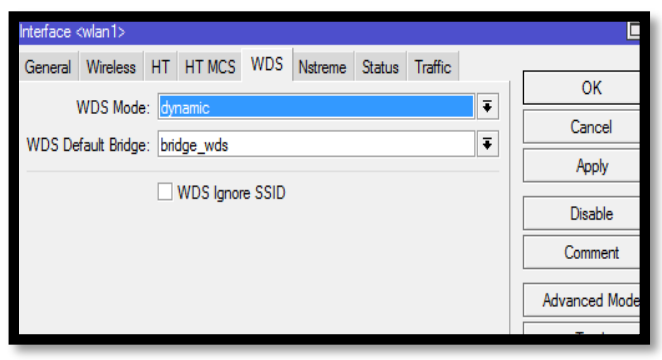

Gambar 6 WDS Dynamic wlan1

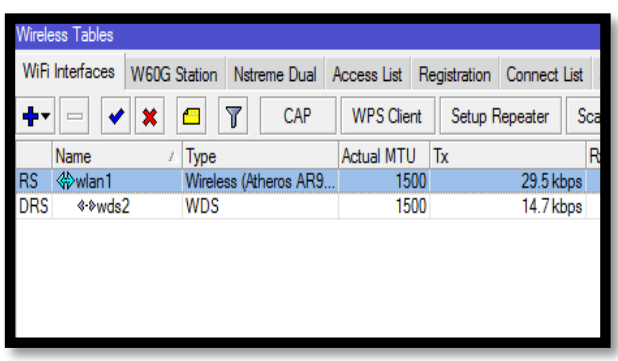

Gambar 7 Wifi Interfaces di WinBox 
Implementasi selanjutnya adalah memberikan password untuk login mikrotik agar lebih aman karena untuk login mikrotik default usernya adalah admin dan tidak ada password sehingga siapapun dapat masuk ke halaman mikrotik. Konfigurasi dilakukan dengan masuk ke menu system $\rightarrow$ user. Kolom name dan password diisikan sesuai dengan keinginan. Pemberian nama dan password dapat dilihat pada Gambar 9.

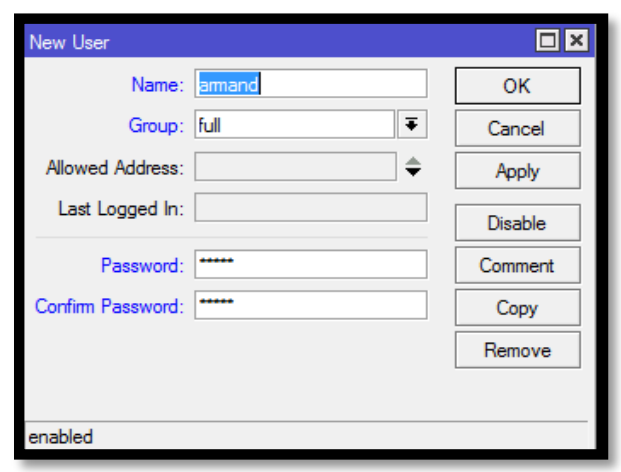

Gambar 8 Membuat user untuk login Mikrotik di WinBox

\section{b. Router Mikrotik RB941 Berfungsi Sebagai Access Point Repeater}

Tahap pertama adalah pemberian nama pada router. Konfigurasi nama dilakukan dengan perintah system identity set name $=R \_$repeater di terminal pada mikrotik. Kemudian membuat interface bridge di mikrotik repeater. Pembuatan bridge dilakukan untuk menghubungkan repeater (router mikrotik RB941) dengan mikrotik utama. Konfigurasi nama dan interface dapat dilihat pada Gambar 10.

[admindR_repeater] > system identity set name=R_repeater

Gambar 9 Konfigurasi pemberian nama router repeater

Selanjutnya dilakukan penambahan interface wlan1 dilakukan untuk menghubungkan wlan1 dengan bridge_repeater. Penambahan interface ether2 kedalam port bridge_repeater dilakukan untuk menghubungkan ether2 dengan bridge_repeater. Interface ether2 adalah interface yang terhubung dari mikrotik ke laptop menggunakan kabel LAN. Pada tab wireless di interface wlan1 dapat dilakukan Scan untuk mencari SSID dari router utama yang telah dibuat. Pada scanner running terdapat status ARWB pada SSID KatinganMentaya yang artinya adalah Active, Routers Network, WDS, Bridge. Tampilan scanner SSID dapat dilihat pada Gambar 11. 


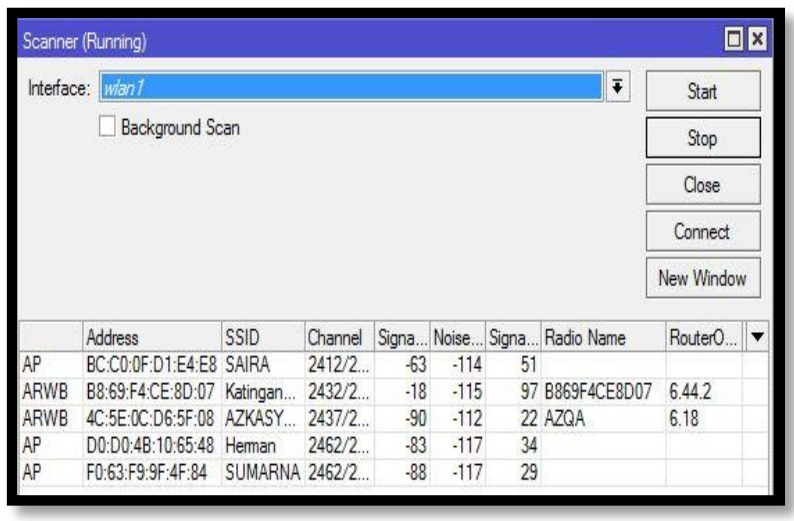

Gambar 10 Scan SSID router utama

Pada tab wireless di interface wlan1 ada pengubahan pada mode wireless menjadi wds slave. Fungsi dari mode wds slave sama dengan ap bridge namun koneksi dilakukan dengan WDS. Pada tab WDS diatur mode yang digunakan adalah dynamic sama seperti router access point utama. Konfigurasinya ditunjukan pada Gambar 12.

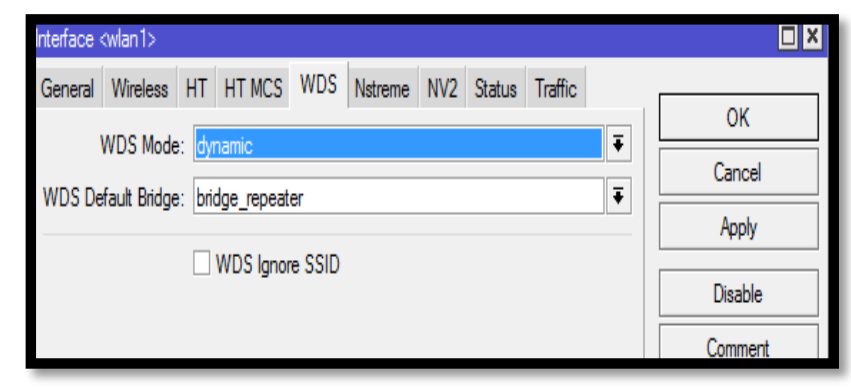

Gambar 11 WDS dynamic wlan1

Pada tab wireless wlan1, ada penambahan interface wlan virtual untuk dijadikan hotspot. Mode yang dipilih adalah ap bridge. Kolom SSID diisikan "KatinganMentaya2" atau bisa juga sesuai dengan keinginan. Master interface adalah wlan1. Virtual $A P$ ini akan terhubung dengan bridge_repeater yang akan membagikan sinyal wifi ke pengguna. Pada mikrotik keterangan Virtual $A P$ yang dibuat adalah wlan2. Konfigurasi SSID dapat dilihat pada Gambar 13. 


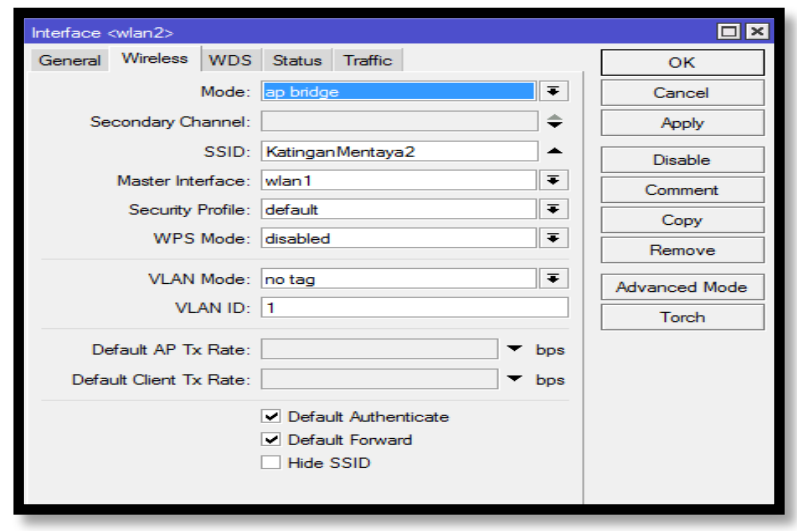

Gambar 12 Mode Virtual AP menjadi AP Bridge

\section{c. Konfigurasi Hotspot dan User Manager}

Tahap Pertama adalah melihat versi dari mikrotik yang digunakan dengan memilih menu System $\rightarrow$ Resources. Informasi tersebut dapat dilihat pada bagian Architecture Name dan Version di WinBox. Versi harus dilihat terlebih dahulu agar tidak terjadi kesalahan saat instalasi user manager. Secara default, package User Manager belum ada pada router. Package dapat diunduh melalui link www.mikrotik.co.id/download.php atau pada halaman www.routeros.co.id. Package yang digunakan harus disesuaikan dengan jenis atau arsitektur router MikroTik yang digunakan. Pada User Manager tidak hanya menambah, menghapus, dan mengubah akun pengguna hostpot saja, di dalam User Manager dapat dilakukan pengaturan bandwidth dan manajemen waktu akun pengguna. Setiap satu akun untuk login hotspot dapat digunakan oleh lebih dari satu pengguna dengan menggunakan shared secret di User Manager. Versi Mikrotik yang digunakan dapat dilihat pada Gambar 14.

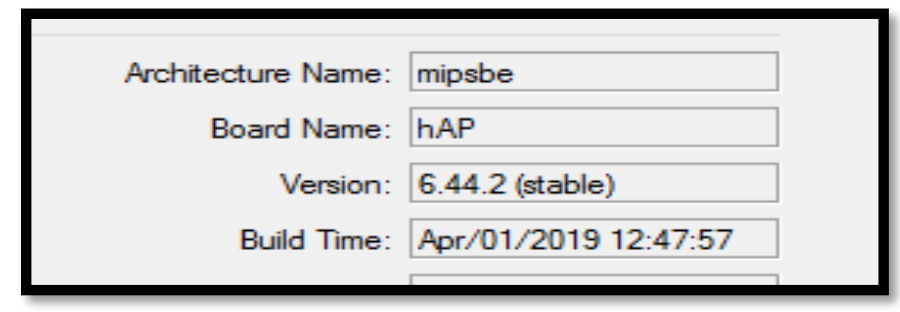

Gambar 13 Versi Mikrotik

Versi file dan package yang diunduh harus sesuai dengan versi router yang digunakan. Setelah berhasil diunduh, file user-manager-6.44.2.npk diunggah ke mikrotik pada menu files di WinBox di router access point utama. Setelah berhasil diunggah, reboot router access point utama. Setelah proses reboot, aplikasi dapat diperiksa melalui WinBox di menu System $\rightarrow$ Packages. Versi file dan package yang digunakan dapat dilihat pada Gambar 15. 


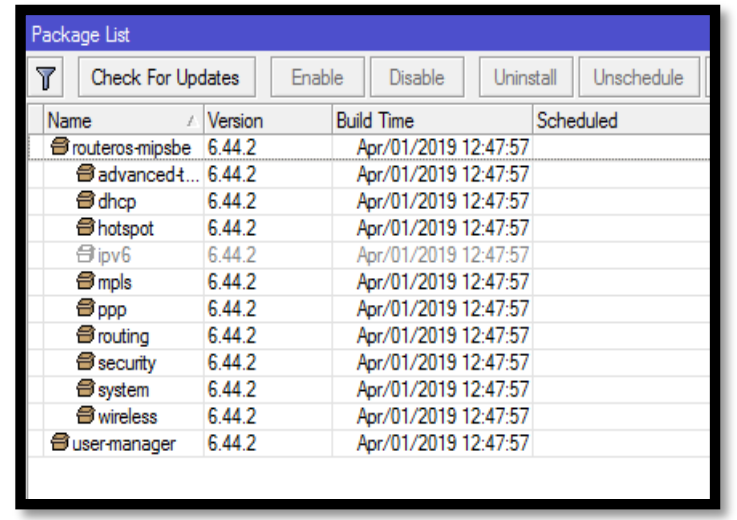

Gambar 14 Package List yang terinstal User Manager

Tahap selanjutnya adalah membuat hotspot server di interface bridge_wds yang telah dibuat sebelumnya. Konfigurasi dilakukan dengan memberikan alamat IP 192.168.8.1/24 sebagai gateway pada jaringan. Pada Hotspot server terdapat DHCP Server yang menyediakan alamat IP secara dinamis terhubung ke pengguna. Range alamat IP yang disediakan yaitu 192.168.8.2-192.168.8.254. Secure Socket Layer (SSL) certificate berfungsi untuk menjaga informasi data saat dikirim melalui internet dengan protokol Hypertext Transfer Protokol Secure (HTTPS), namun sertifikat SSL tidak tersedia. Simple Mail Transfer Protocol (SMTP) adalah protokol di jaringan internet yang berfungsi untuk mengirimkan pesan email. Domain Name System (DNS) berfungsi menterjemahkan alamat IP menjadi nama domain. Pada DNS, IP yang diberikan adalah IP dari interface hotspot yaitu 192.168.8.1 dan nama domainnya adalah "wds-mikrotik.com". Untuk dapat login ke website wdsmikrotik.com harus terlebih dahulu memasukan username dan password. Pengguna yang dapat login pertama kali adalah admin. Konfigurasi pada dilihat pada Gambar 16.

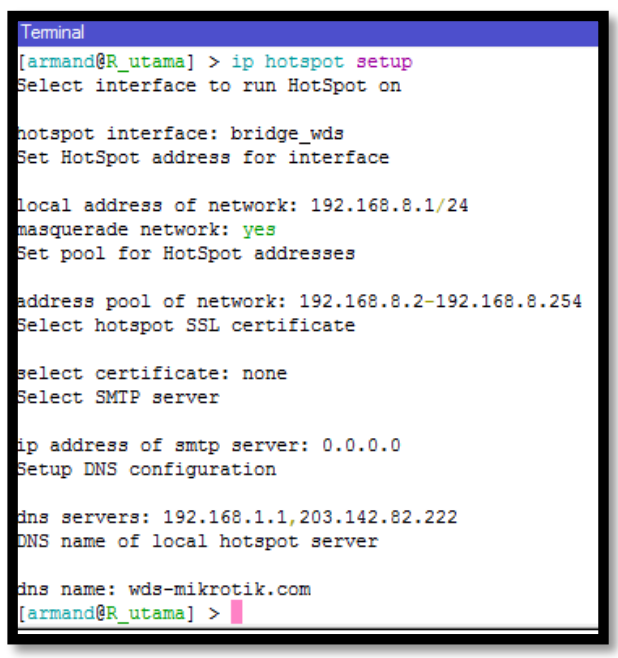

Gambar 15 Konfigurasi Hotspot 
Konfigurasi selanjutnya adalah laptop admin harus terhubung dengan jaringan Wi-Fi yang sudah dibuat yaitu "KatinganMentaya" dan masuk ke halaman User Manager. Konfigurasi User Manager dilakukan pada browser dengan memasukan IP Mikrotik/Userman, alamat IP yang digunakan adalah http://192.168.88.1/userman. Untuk bisa login, admin harus memasukan terlebih dahulu username dan passwordnya.

Pada konfigurasi selanjutnya adalah konfigurasi User Manager agar dapat menerima permintaan autentikasi Hotspot Server. Pada WinBox di menu Routers $\rightarrow$ tombol add, kolom Name diisikan dengan identity atau keterangan nama dari Router utama. Kolom IP Address diisikan dengan 127.0.0.1 karena Hotspot Server dan User Manager berada di router yang sama yaitu router MikroTik utama. Konfigurasinya ditunjukkan pada. Implementasi selanjutnya adalah konfigurasi create profile menu Profiles $\rightarrow$ tab Limitations $\rightarrow$ pilih Add $\rightarrow$ pilih New. Pada kolom Name diisikan nama profile yang akan dibuat yaitu Admin, Staf, dan Manager.

Selanjutnya masing masing profile di konfigurasi di pengaturan masing masing profile. Konfigurasi dilakukan pada Profiles $\rightarrow$ tab Profiles $\rightarrow$ Tombol + . Pada kolom name diisikan nama profile yang dibuat sebelumnya yaitu Admin, Staf, dan Manager. Konfigurasi profile dapat dilihat pada Gambar 17.

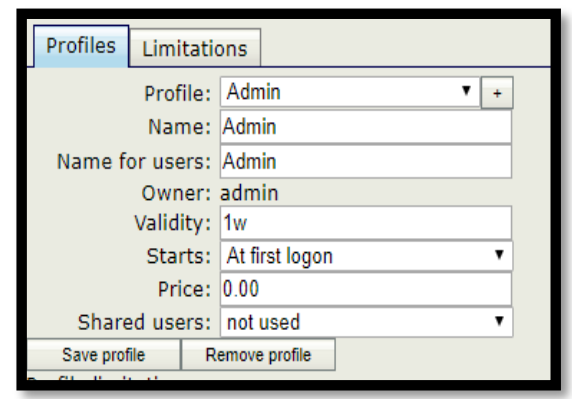

Gambar 17 Pengaturan profile Admin

Pengaturan pembatasan pada masing - masing profile. Pada menu limitation terdapat pilihan hari (days) dari minggu sampai dengan sabtu dan juga jam. Keterangan hari merupakan hari dimana akun profile (Admin, Manager, dan Staf) bisa digunakan pada hari yang telah dipilih. Keterangan jam (Time) merupakan waktu dimana akun bisa digunakan antara jam yang telah diatur waktunya. Setiap pengguna dapat menggunakan akun untuk mengakses internet setiap hari (Minggu sampai Sabtu) dan untuk waktunya setiap pengguna dapat menggunakan akun untuk log in dan mengakses internet selama 24 jam. Pengaturan hari dan waktu profile dapat dilihat pada Gambar 18. 


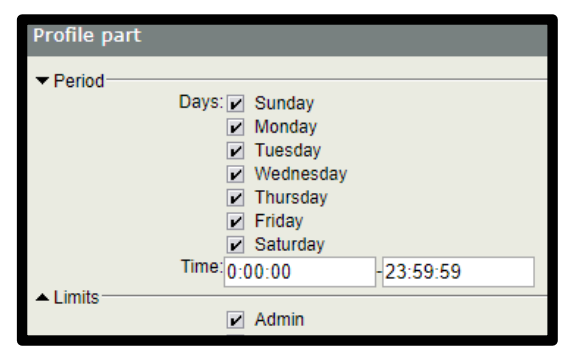

Gambar 18 Pengaturan periode Limit Admin

Langkah selanjutnya membatasi kecepatan pada setiap profile untuk pengguna. Konfigurasi dilakukan pada menu Profiles $\rightarrow$ tab Limitations $\rightarrow$ Add $\rightarrow$ New limit. Kolom Name, Rate Limit, dan Min Rate diisikan nilainya sesuai dengan perancangan yang dibuat.

Pengaturan batasan pada masing-masing profile di User Manager dilakukan untuk membatasi kecepatan akses pada setiap pengguna. profile Admin diberikan kecepatan akses pada parameter rate limits sebesar $1 \mathrm{Mbps}$. Setiap pengguna yang menggunakan profile Admin akan mendapatkan kecepatan akses maksimal 1Mbps untuk download dan upload. Profile Staf akan diberikan kecepatan akses pada parameter rate limits sebesar $512 \mathrm{Kbps}$. Setiap pengguna yang menggunakan profile Staf akan mendapatkan kecepatan akses maksimal 512 Kbps untuk download dan upload. Profile Manager akan diberikan kecepatan akses pada parameter rate limits sebesar 1 Mbps. Setiap pengguna yang menggunakan profile Manager akan mendapatkan kecepatan akses maksimal 1 Mbps untuk download dan upload. Pengaturan batasan dapat dilihat pada Gambar 19.

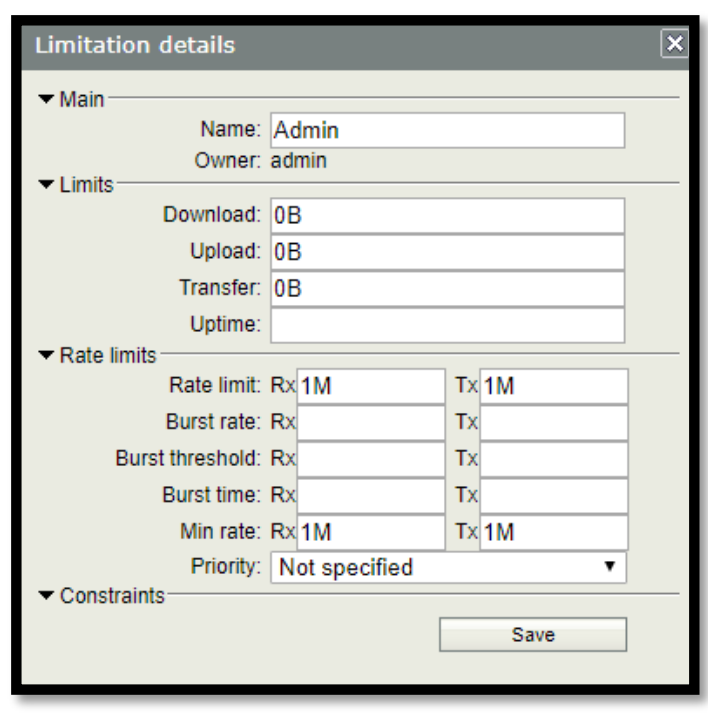

Gambar 19 Pengaturan Limitation bandwidth Admin

Berdasarkan tahap perancangan, Admin dibuat lima account, Manager akan dibuat 10 account, dan Staf akan dibuat 15 account. Konfigurasi pembuatan account 
dilakukan pada menu User $\rightarrow$ tombol Add $\rightarrow$ pilih Batch. Kolom Number of users diisikan dengan jumlah account yang ingin dibuat. Kolom username prefix untuk memudahkan melihat jenis account yang dibuat. Kolom username length disesuaikan dengan banyak username yang ingin dibuat. Kolom Pwd same as login tidak dipilih agar password tidak sama dengan username. Kolom Password length disesuaikan dengan panjang karakter pada password yang ingin dibuat. Pembuatan account dapat dilihat pada Gambar 20.

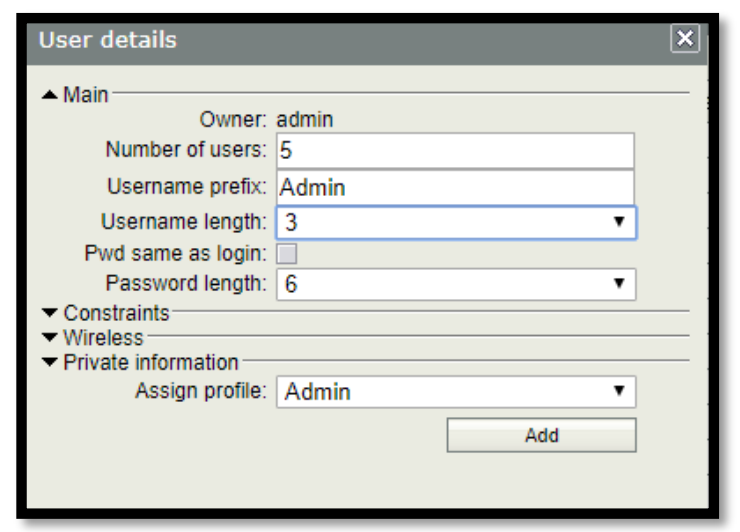

Gambar 20 Pembuatan akun Admin

\section{d. Pengujian}

Pengujian dilakukan sebagai pembuktian bahwa WDS yang telah di konfigurasi pada kedua router access point sudah saling terhubung dan hotspot yang telah dibuat sudah siap digunakan oleh pengguna.

Pengujian pertama adalah dengan melihat SSID dari Hotspot mikrotik sudah tersedia atau belum. Jika sudah tersedia maka akan muncul SSID dan bisa terhubung dengan Wifi. SSID "KatinganMentaya" adalah SSID router mikrotik utama, sedangkan SSID "KatinganMentaya2" adalah SSID router mikrotik repeater.

Pengujian kedua adalah test ping IP dari router utama ke router repeater dan ping sebaliknya pada terminal di WinBox. Pengujian ini dilakukan di kedua router mikrotik. Pengujian PING dapat dilihat pada Gambar 21. Hasil dari pengujian ini terlihat bahwa router repeater dapat diakses dari router utama. Tes ping menghasilkan $100 \%$ data dapat terkirim dan diterima oleh router repeater.

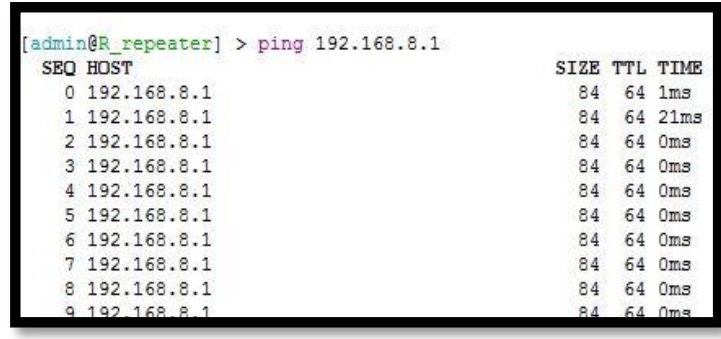

Gambar 21 Ping IP address 
Pengujian ketiga adalah menguji autentikasi username dan password user manager di web browser untuk login agar dapat terhubung ke internet. Username dan password yang tidak terdaftar di User Manager saat digunakan untuk login akan muncul keterangan invalid username or password maka pengguna tidak bisa login dan terkoneksi ke internet. Apabila username dan password terdaftar maka pengguna dapat login dan terkoneksi ke internet dan akan muncul status dari account yang digunakan.

\section{SIMPULAN}

Pembuatan WDS pada kedua router telah dilakukan. Berdasarkan hasil pengujian dapat disimpulkan bahwa jangkauan wireless menjangkau seluruh area gedung PT Rimba Makmur Utama. Jaringan wireless dibangun dengan menggunakan WDS pada dua access point sebagai access point utama dan access point repeater. WDS yang dibuat bersifat dinamis. Pengaturan satu username dan password hanya bisa dilakukan oleh satu pengguna sudah berhasil dilakukan. Router repeater dapat menerima $100 \%$ paket data dari router utama, sehingga dapat disimpulkan seluruh gedung terkoneksi dengan jaringan internet.

\section{DAFTAR PUSTAKA}

Budhathoki DR . 1994. Computer Network : Lecture Notes [Internet] [Diunduh 14 Juni 2019] Tersedia pada https://dayaramb.files.wordpress.com/2011/03/computer-network-notes-pu.pdf

Chris N. 2012 . Mikrotik Switch "Router+Switch". Jakarta (ID) : Citraweb Nusa Infomedia

Firdaus G.2014. Integrasi Hotspot dengan User Manager [internet]. [diunduh 2019 Maret 2]. Tersedia pada : http://mikrotik.co.id/artikel_lihat.php?id=46.

Miftah Z. 2018. Simulasi Keamanan Jaringan dengan Metode DHCP Snooping dan VLAN [Internet] [Diunduh pada tanggal 24 Juni 2019] Faktor Exacta 11(2): 167-178 Tersedia pada https://www.researchgate.net/publication/331706840_SIMULASI_KEAMANAN _JARINGAN_DENGAN_METODE_DHCP_SNOOPING_DAN_VLAN.pdf

Nimishan P, Rajan G, Dhiren G. 2009. Packet Sniffing : Network Wirettaping. India (IN) : International Advance Computing Conference

Roobi . 2018. Metode Autentikasi Mikrotik [internet] . [Diunduh pada tanggal 28 Juni 2019] LenTerra Tech. Tersedia pada : http://lenterratech.id/2018/10/26/metode-autentikasi-hotspot-mikrotik

Sukaridhoto S. 2014. Buku Jaringan Komputer Satu. Surabaya (ID) : Politeknik Elekronika Negeri Surabaya. 